\title{
Self-assembly of Fmoc-tetrapeptides based on the RGDS cell adhesion motif
}

Article

Accepted Version

Castelletto, V., Moulton, C. M., Cheng, G., Hamley, I. W., Hicks, M. R., Rodger, A., López-Pérez, D. E., Revilla-LópezPérez, G. and Alemán, C. (2011) Self-assembly of Fmoctetrapeptides based on the RGDS cell adhesion motif. Soft Matter, 7 (24). pp. 11405-11415. ISSN 1744-683X doi: https://doi.org/10.1039/C1SM06550E Available at https://centaur.reading.ac.uk/25317/

It is advisable to refer to the publisher's version if you intend to cite from the work. See Guidance on citing.

To link to this article DOI: http://dx.doi.org/10.1039/C1SM06550E

Publisher: Royal Society of Chemistry

All outputs in CentAUR are protected by Intellectual Property Rights law, including copyright law. Copyright and IPR is retained by the creators or other copyright holders. Terms and conditions for use of this material are defined in the End User Agreement.

www.reading.ac.uk/centaur 
Central Archive at the University of Reading

Reading's research outputs online 


\section{Self-Assembly of Fmoc-Tetrapeptides Based on the RGDS Cell Adhesion Motif}

V. Castelletto, C. M. Moulton, G. Cheng, I. W. Hamley,*

School of Chemistry, Pharmacy and Food Biosciences, University of Reading, Reading RG6 6AD, U.K.

Matthew R. Hicks, Alison Rodger

Department of Chemistry, University of Warwick, Coventry CV4 7AL, U.K.

Daniel E. López-Pérez, Guillermo Revilla-López, and Carlos Alemán

Departament d'Enginyeria Química, E. T. S. d'Enginyeria Industrial de Barcelona and Center for Research in NanoEngineering, Universitat Politècnica de Catalunya, Diagonal 647, 08028 Barcelona, Spain.

Revised 20/9/11.

* Author for correspondence. 


\begin{abstract}
Self-assembly in aqueous solution has been investigated for two Fmoc $[\mathrm{Fmoc}=\mathrm{N}$ (fluorenyl)-9-methoxycarbonyl] tetrapeptides comprising the RGDS cell adhesion motif from fibronectin or the scrambled sequence GRDS. The hydrophobic Fmoc unit confers amphiphilicity on the molecules, and introduces aromatic stacking interactions. Circular dichroism and FTIR spectroscopy show that the self-assembly of both peptides at low concentration is dominated by interactions among Fmoc units, although Fmoc-GRDS shows $\beta$-sheet features, at lower concentration than FmocRGDS. Fibre X-ray diffraction suggests $\beta$-sheet formation by both peptides at sufficiently high concentration. Strong alignment effects are revealed by linear dichroism experiments for Fmoc-GRDS. Cryo-TEM and small-angle X-ray scattering (SAXS) reveal that both samples form fibrils with a diameter of approximately $10 \mathrm{~nm}$. The SAXS intensity profile for Fmoc-RGDS can be fitted with a model cylinder form factor, however for Fmoc-GRDS the SAXS data is more consistent with a fractal network structure of fibrils. Both Fmoc-tetrapeptides form self-supporting hydrogels at sufficiently high concentration. Dynamic shear rheometry enabled measurements of the moduli for the Fmoc-GRDS hydrogel, however significant syneresis was observed for the Fmoc-RGDS hydrogel which was significantly less stable to shear. Molecular dynamics computer simulations indicate that an antiparallel $\beta$-sheet configuration is clearly favoured for Fmoc-RGDS although there is less difference in total internal energy of parallel and antiparallel $\beta$-sheet configurations of Fmoc-GRDS.
\end{abstract}




\section{Introduction}

Amphiphilic peptides enable the creation of novel self-assembling systems which incorporate the biofunctionality offered by the diversity of natural amino acids. ${ }^{1-5} \mathrm{~A}$ number of strategies may be adopted to build in amphiphilicity. Hydrophilic peptides may be attached to alkyl chains to produce peptide amphiphiles or other hydrophobic units. Alternatively, hydrophobic peptides may be linked to hydrophilic chains such as poly(ethylene glycol), leading in the polymeric limit to polymer-peptide conjugates.

Fmoc-dipeptides and Fmoc-tripeptides $[$ Fmoc $=$ N-(fluorenyl-9-methoxycarbonyl) $]$ containing hydrophilic residues can be considered as amphiphilic peptides since the Fmoc unit is hydrophobic. However, the main driving force for self-assembly is $\pi-\pi$ stacking of the aromatic Fmoc units. This has been established by work in several groups. ${ }^{6-15}$

Here, we investigate the use of Fmoc as a motif to control the self-assembly of the bioactive peptide RGDS. This peptide is part of a sequence from fibronectin. ${ }^{16-18}$ The tetrapeptide sequence and more especially the tripeptide RGD subunit are widely employed in the development of bionanomaterials for applications in cell growth/differentiation or tissue scaffolding. ${ }^{19}$ The RGDS tetrapeptide has antithrombotic activity due to the inhibition of platelet aggregation resulting from the fibrinogen recognition sequence. ${ }^{20,21}$ The bioactive RGDS motif has also been incorporated into peptide amphiphiles (PAs), ${ }^{22-24}$ including a PA based on the hydrophobic Fmoc unit. $^{25}$ The self-assembly of materials containing RGD-peptide sequences has been reviewed elsewhere., ${ }^{56}$ Among recent examples, a designed 
peptide containing the RGDS motif has been shown to form fibrils in the presence of $\mathrm{Mg}^{2+}$ ions, and the fibrous hydrogel was shown to be capable to absorb growth factors and cytokines released by embryonic stem cells. ${ }^{27}$ In another example, incorporation of the RGD motif within an amyloid peptide containing an 11-residue sequence from transthyretin led to bioactive materials with fibroblast cell adhesion properties. ${ }^{28} \mathrm{We}$ have recently reported on the self-assembly of Fmoc-RGD compared to Fmoc-GRD. ${ }^{29}$ Fibrillar structures based on $\beta$-sheet self-assembly were observed for both peptides, hydrogelation was noted at sufficiently high concentration, and the dynamic mechanical response of the hydrogels was measured. In contrast to Fmoc-RGD, the control Fmoc-GRD containing a scrambled tripeptide sequence formed cloudy hydrogels which was ascribed to the formation of clusters of fibrils (supported by analysis of in situ SAXS data). Preliminary cell culturing experiments using bovine fibroblasts established that cell viability is retained for Fmoc-RGD, but not FmocGRD. Although the RGD sequence is widely used in the development of model systems, the RGDS tetrapeptide is expected to have enhanced bioactivity due to the additional serine residue. ${ }^{16,26,30-32}$

Here, we report on an investigation of the self-assembly in aqueous solution of two Fmoc-tetrapeptides, Fmoc-RGDS and Fmoc-GRDS. The former contains the RGDS adhesion motif, while the latter is a control containing the same residues but in a scrambled sequence. The secondary structure is probed via FTIR specotroscopy and circular dichroism (CD) spectroscopy, complemented by UV linear dichroism (LD) spectroscopy to examine alignment effects. Fibril formation is examined using cryogenic transmission electron microscopy (cryo-TEM), and confirmed by in situ small-angle X-ray scattering (SAXS) experiments. The rheological properties of 
hydrogels formed by the two peptides are compared. In addition, we compare the selfassembly of the two Fmoc-tetrapeptides with our previous data on the Fmoctripeptides lacking the terminal serine residue.

\section{Experimental}

Some of the studies reported herein were performed with peptides synthesized inhouse, whilst others used peptides obtained commercially. The purchased samples of Fmoc-GRDS and Fmoc-RGDS were obtained from CS Bio (Menlo Park, USA). For Fmoc-GRDS, the purity was $98.76 \%$ (by HPLC in a TFA/water/acetonitrile gradient system). Molecular weight obtained by electrospray-mass spectrometry was 655.60 (expected: 655.67). For Fmoc-RGDS, the purity was $99.41 \%$ (by HPLC in a TFA/water/acetonitrile gradient system). Molecular weight obtained by electrospraymass spectrometry was 655.87 (expected: 655.67).

For the in-house synthesis, Fmoc-Arg(Pbf)-OH, Fmoc-Gly-OH, Fmoc Asp(OtBu)OH, Fmoc-Ser( $t \mathrm{Bu})$-Wang resin (100-200 mesh), diisopropylethylamine (DIPEA), HOBt (1-hydroxybenzotriazole) and HBTU [2-(1H-benzotriazol-1-yl)-1,1,3,3tetramethyluronium hexafluorophosphate] were purchased from Novabiochem (United Kingdom). Anhydrous N,N-dimethylformamide (DMF), trifluoroacetic acid (TFA) piperidine, triisopropylsilane (TIPS) and Congo red were purchased from SigmaAldrich (United Kingdom); acetonitrile (HPLC grade) and water (HPLC grade) were purchased from Fisher Scientific (United Kingdom).

Fmoc peptide synthesis and purification 
Fmoc peptides were synthesized on a $0.45 \mathrm{mM}$ scale using a standard Fmoc chemistry procedure with a sintered glass funnel. After the resin was swelled in DMF for $30 \mathrm{~min}$ it was drained and treated with piperidine in DMF (1:4 ) to deprotect the Fmoc group. The reaction mixture was agitated for $10 \mathrm{~min}$ by nitrogen bubbling and then drained. After the piperidine treatment was repeated three times, the solution was drained and washed with DMF $(6 \times)$, followed by coupling with activated Fmoc-protected amino acids. Three equiv. of Fmoc-Xxx-OH to resin loading and 3 equiv HBTU / HOBt were dissolved in the minimum amount of DMF necessary, followed by addition of 5.0 equiv. (iPr) ${ }_{2}$ Net. The mixture was allowed to stand for 5 minutes prior to adding to the drained resin. The coupling reaction was then agitated for $1.5 \mathrm{~h}$ by nitrogen bubbling, drained and washed with DMF $(6 \times)$. The drained resin was treated with piperidine in DMF (1:4 ) to deprotect the Fmoc group for coupling with Fmocprotected amino acids. After completion of the peptide sequence by repetition of the above steps, the resin was washed with DMF $(4 \times), \mathrm{MeOH}(4 \times), \mathrm{CH}_{2} \mathrm{Cl}_{2}(4 \times)$ and dried under vacuum for an hour prior to TFA-mediated cleavage. In the cleavage step, the obtained peptide attached to the solid support was treated with a mixture of $95 \%$ TFA, $2.5 \%$ triisopropylsilane, and $2.5 \%$ water, and the mixture was stirred at room temperature for approximately $4 \mathrm{~h}$, followed by filtration. The cleaved resin was washed three times with TFA. The obtained peptide solution was collected and concentrated by evaporating TFA under vacuum, followed by precipitation in cold diethyl ether. The crude product was separated by centrifugation and decanting of the supernatant.

The crude peptide was redissolved in a HPLC grade water/acetonitrile co-solvent mixture for RP-HPLC purification. Preparative reverse-phase HPLC was carried out 
on a Perkin-Elmer 200 system using a C18 column (Macherey-Nagel, $7 \mu \mathrm{m}, 10 \mathrm{~mm} \times$ $250 \mathrm{~mm})$ at $35^{\circ} \mathrm{C}$ (Perkin-Elmer Series 200 Peltier Column Oven) with UV/vis detector (Perkin-Elmer Series $200 \mathrm{UV} /$ vis Detector) at $254 \mathrm{~nm}$. The eluents, $0.1 \%$ TFA in acetonitrile and $0.1 \%$ aqueous TFA, were used as a gradient solvent system in the RPHPLC, where the acetonitrile portion increased linearly from $0 \%$ to $90 \%$ over $20 \mathrm{~min}$ and then decreased linearly to $0 \%$ over $10 \mathrm{~min}$ with a flow rate of $4 \mathrm{ml} / \mathrm{min}$. A UV/vis detector monitored the sample elution at 238 or $254 \mathrm{~nm}$. The fractions of the peptide were collected, followed by lyophilization to give a white solid, which was characterized by electrospray-MS and ${ }^{1} \mathrm{H}$ NMR.

Fmoc-RGDS as a white powder $\left(\mathrm{RP}-\mathrm{HPLC}, \mathrm{t}_{R}=13.88 \mathrm{~min}\right)$ : MS: calc. $[\mathrm{M}]^{+}=$ 655.26, found $[\mathrm{M}+\mathrm{H}]^{+}=656.27 ;{ }^{1} \mathrm{H}$ NMR $\left(400 \mathrm{MHz}, \mathrm{MeOH}-\mathrm{d}_{4}\right) \delta(\mathrm{ppm}): 1.55(\mathrm{~m}$, 3H), $1.73(\mathrm{~m}, 1 \mathrm{H}), 2.68(\mathrm{dd}, \mathrm{J}=17.2 \mathrm{~Hz}, 7.6 \mathrm{~Hz}, 1 \mathrm{H}), 2.80(\mathrm{dd}, \mathrm{J}=17.0 \mathrm{~Hz}, 5.6 \mathrm{~Hz}$, 1H), 3.08(t, J = 6.4 Hz, 2H) , 3.79(m, 4H), $3.99(\mathrm{t}, \mathrm{J}=7.2 \mathrm{~Hz}, 1 \mathrm{H}), 4.13(\mathrm{t}, \mathrm{J}=6.4 \mathrm{~Hz}$, $1 \mathrm{H}), 4.37(\mathrm{~m}, 4 \mathrm{H}), 7.21(\mathrm{t}, \mathrm{J}=7.6 \mathrm{~Hz}, 2 \mathrm{H}), 7.31(\mathrm{t}, \mathrm{J}=7.6 \mathrm{~Hz}, 2 \mathrm{H}), 7.57(\mathrm{t}, \mathrm{J}=8.0$ $\mathrm{Hz}, 2 \mathrm{H}), 7.71(\mathrm{~d}, \mathrm{~J}=7.6 \mathrm{~Hz}, 2 \mathrm{H}$ ), 7.88, 8.22, 8.39 [amide-H].

Fmoc-GRDS as a white powder (RP-HPLC, $\left.\mathrm{t}_{R}=13.56 \mathrm{~min}\right)$ : MS: calc. $[\mathrm{M}]^{+}=$ 655.26, found $[\mathrm{M}+\mathrm{H}]^{+}=656.27 ;{ }^{1} \mathrm{H}$ NMR $\left(400 \mathrm{MHz}, \mathrm{MeOH}-\mathrm{d}_{4}\right) \delta(\mathrm{ppm}): 1.56(\mathrm{~m}$, 3H), $1.81(\mathrm{~m}, 1 \mathrm{H}), 2.66(\mathrm{dd}, \mathrm{J}=16.8 \mathrm{~Hz}, 8.0 \mathrm{~Hz}, 1 \mathrm{H}), 2.84(\mathrm{dd}, \mathrm{J}=16.8 \mathrm{~Hz}, 4.8 \mathrm{~Hz}$, 1H), $3.08(\mathrm{t}, \mathrm{J}=6.8 \mathrm{~Hz}, 2 \mathrm{H}), 3.71(\mathrm{~m}, 4 \mathrm{H}), 3.81(\mathrm{dd}, \mathrm{J}=11.6 \mathrm{~Hz}, 4.4 \mathrm{~Hz}, 1 \mathrm{H}), 4.14(\mathrm{t}$, $\mathrm{J}=6.4 \mathrm{~Hz}, 1 \mathrm{H}), 4.29(\mathrm{~m}, 4 \mathrm{H}), 7.22(\mathrm{td}, \mathrm{J}=7.6 \mathrm{~Hz}, 1.2 \mathrm{~Hz}, 2 \mathrm{H}), 7.30(\mathrm{t}, \mathrm{J}=7.6 \mathrm{~Hz}$, 2H), $7.58(\mathrm{~d}, \mathrm{~J}=7.6 \mathrm{~Hz}, 2 \mathrm{H}), 7.71(\mathrm{~d}, \mathrm{~J}=7.6 \mathrm{~Hz}, 2 \mathrm{H}), 7.83,8.21$ [amide-H].

\section{Hydrogel Formation}

Each Fmoc-tripeptide was added into a vial, followed by addition of water to make up the desired concentration. The mixture was sonicated in an ultrasonic bath with 
shaking at $45-55^{\circ} \mathrm{C}$ for 5-10 minutes to produce a clear Fmoc-tetrapeptide solution. Upon cooling to room temperature it was allowed to stand overnight and gelation was observed by the inverted vial method.

Circular Dichroism (CD) and Linear Dichroism (LD)

CD spectra for $1 \mathrm{wt} \%$ peptide solutions were recorded at room temperature using a Chirascan spectropolarimeter (Applied Photophysics, UK). Solutions were loaded in parallel plaque cells (Hellma quartz Suprasil@), with a nominal $0.01 \mathrm{~mm}$ path length. The CD data were measured using $1 \mathrm{sec}$ acquisition time per point and $0.5 \mathrm{~nm}$ step. The post-acquisition smoothing tool from Chirascan software was used to remove random noise elements from the averaged spectra. A residual plot was generated for each curve in order to verify whether or not the spectrum has been distorted during the smoothing process. The $\mathrm{CD}$ signal from the water was subtracted from the $\mathrm{CD}$ data of the peptide solutions. For CD the path length was $1 \mathrm{~mm}$ for the $0.02 \mathrm{wt} \%$ samples using Spectrosil quartz cuvettes (Starna Optiglass, Hainault, UK). Note that the sample was placed directly adjacent to the photomultiplier tube in order to minimize loss of light due to scattering. The samples were mounted with the long axis of the cuvette either vertical or horizontal using a modified cell holder.

Linear dichroism measurements on samples with $0.02 \mathrm{wt} \%$ or $0.2 \mathrm{wt} \%$ peptide concentration were performed at room temperature $\left(21{ }^{\circ} \mathrm{C}\right)$ on a Jasco J-815 spectropolarimeter modified for linear dichroism (Jasco UK, Great Dunmow, UK). Spectra were measured between 350 and $180 \mathrm{~nm}$ with a step size of $0.2 \mathrm{~nm}$. Data was truncated below the wavelength at which the HT reading indicated that there was not enough light incident on the detector. The bandwidth was set to $1 \mathrm{~nm}$ with a scanning 
speed of $100 \mathrm{~nm} \mathrm{~min}{ }^{-1}$ and a digital integration time of $1 \mathrm{~s}$. In order to improve the signal to noise, triplicate spectra were measured and averaged.

For Couette LD measurements, alignment of the samples was achieved using a microvolume Couette cell with a path length of $0.5 \mathrm{~mm}$ and rotation speed of 3000 rpm, which was built in-house ${ }^{33,34}$ (equivalent models are available from Kromatek, Great Dunmow, UK). Three spectra were averaged and a water baseline spectrum was subtracted from this to account for the inherent LD signal of the system originating from the optics and the detector. LD spectra are reported in $\Delta$ absorbance units.

\section{Fourier Transform Infra-Red (FTIR) Spectroscopy}

Spectra were recorded using a Nexus-FTIR spectrometer equipped with a DTGS detector. Solutions of Fmoc-tetrapeptide in $\mathrm{D}_{2} \mathrm{O}$ with concentrations of 1 or 3 wt $\%$ were sandwiched in ring spacers between two $\mathrm{CaF}_{2}$ plate windows (spacer $25 \mu \mathrm{m}$ ). All spectra were scanned 128 times over the range of $4000-950 \mathrm{~cm}^{-1}$.

\section{Cryogenic-Transmission Electron Microscopy (Cryo-TEM)}

Experiments were performed at Unilever Research, Colworth, Bedford, UK. Sample preparation was carried out using a CryoPlunge 3 unit (Gatan Instruments) employing a double blot technique. $3 \mu \mathrm{l}$ of sample was pipetted onto a plasma etched (15 s) 400 mesh holey carbon grid (Agar Scientific) held in the plunge chamber at approx 90\% humidity. The samples were blotted, from both sides for $0.5,0.8$ or $1.0 \mathrm{~s}$ dependant on sample viscosity. The samples were then plunged into liquid ethane at a temperature of $-170{ }^{\circ} \mathrm{C}$. The grids were blotted to remove excess ethane then transferred, under liquid nitrogen to the cryo TEM specimen holder (Gatan 626 cryo holder) at $-170{ }^{\circ} \mathrm{C}$. 
Samples were examined using a Jeol 2100 TEM operated at $200 \mathrm{kV}$ and imaged using a Gatan Ultrascan 4000 camera and images captured using DigitalMicrograph software (Gatan).

\section{Small-Angle X-ray Scattering (SAXS)}

Experiments were performed on beamline ID02 at the ESRF, Grenoble, France. The sample was mounted into a glass capillary flow-through cell within a metal chamber heated by a water bath. The data presented are averages of ten frames, taken at different sample positions. The sample-to-detector distance was $1 \mathrm{~m}$ and the X-ray wavelength was $\lambda=0.995 \AA$. The $q=4 \pi \sin \theta / \lambda$ scale (here $2 \theta$ is the scattering angle) was calibrated using silver behenate.

\section{Fibre X-ray Diffraction}

X-ray diffraction was performed on stalks prepared from $2 \mathrm{wt} \%$ solutions in water. The stalks were mounted (vertically) onto the four axis goniometer of a RAXIS IV++ X-ray diffractometer (Rigaku) equipped with a rotating anode generator. The XRD data was collected using a Saturn 992 CCD camera.

\section{Rheology}

The rheological properties of the systems were determined at $25^{\circ} \mathrm{C}$, using a controlled stress AR-2000 rheometer from TA Instruments. A cone and plate geometry $(20 \mathrm{~mm}$ diameter, $1^{\circ}$ angle) was used for both samples. Preliminary strain sweeps (frequency $\omega=1 \mathrm{~Hz}$ ) were measured to determine the linear regime and ensure that the moduli were independent of strain. Then, frequency sweeps were performed for $\omega=0.1-600$ 
$\operatorname{rad~} \mathrm{s}^{-1}$, with the oscillatory stress fixed to $0.2 \mathrm{~Pa}$, and strain values within the linear regime $(0.01 \%-0.03 \%)$.

\section{Computer Simulation}

All Molecular Dynamics (MD) simulations were performed using the AMBER forcefield. ${ }^{35,36}$ RESP charges for Fmoc moiety were derived at HF/6-31G* level. Atom pair distance cut-offs were applied at $14.0 \AA$ to compute the van der Waals and electrostatic interactions. To avoid discontinuities in the potential energy function, the van der Waals energy term was forced to slowly converge to zero by applying a smoothing factor from a distance of $12.0 \AA$. Electrostatic interactions were computed using the non-truncated electrostatic potential with Ewald summations. ${ }^{37}$ The real space term was determined by the van der Waals cutoff (14.0 $\mathrm{A})$, while the reciprocal term was estimated by interpolation of the effective charge into a charge mesh with a grid thickness of 5 points per volume unit, i.e., using the particle-mesh Ewald (PME) method. Both temperature and pressure were controlled by the weak coupling method, the Berendsen thermobarostat, ${ }^{38}$ using a time constant for heat bath coupling and a pressure relaxation time of 1 ps. Bond lengths were constrained using the SHAKE algorithm $^{39}$ with a numerical integration step of 2 fs. All MD simulations were performed using the NAMD program. ${ }^{40}$ Simulations were carried considering the following systems: (i) $n$ explicit Fmoc-RGDS peptide molecules (with $n=7$ or 21 ) assembled in one strand forming $n-1 \beta$-sheets, which adopt parallel or antiparallel arrangements (denoted p/Fmoc-RGDS and a/Fmoc-RGDS systems, respectively); and (ii) $n$ explicit Fmoc-GRDS peptide molecules (with $n=7$ or 21) assembled in one strand forming $n-1 \beta$-sheets, which adopt parallel or antiparallel arrangements (p/Fmoc-GRDS and a/Fmoc-GRDS systems, respectively). Figure 10 shows the 
starting structures for the four simulations with $n=21$ explicit peptide molecules. Neutralization of the charge at $\mathrm{pH}=7$ was achieved by adding 7 and $21 \mathrm{Na}^{+}$counterions for systems with $n=7$ and 21, respectively. The p/Fmoc-RGDS, a/Fmoc-RGDS, p/Fmoc-GRDS and a/Fmoc-GRDS systems with $n=7$ were solvated by including 16237, 16679, 14691 and $14935 \mathrm{TIP}^{4} \mathrm{P}^{41}$ water molecules, respectively, whereas the number of explicit water molecules used for simulations with $n=21$ were 290392 , 290114 and 290478, respectively.

Each system was equilibrated by running a NVT-MD simulation at $310 \mathrm{~K}$ for $1 \mathrm{~ns}$, the resulting atom velocities and coordinates being used to start a 2 ns of NPT MD (298 $\mathrm{K}, 1$ bar pressure) simulation to equilibrate density to $1 \mathrm{~g} \mathrm{~cm}^{-3}$. Constraints to maintain inter-chain distances were applied through all the equilibration period. Productive simulation for systems with $n=7$ or 21 consisted in 20 and 10 ns NPT MD ( 298 K, 1 bar pressure) runs, respectively, which were started using the coordinates and atom velocities obtained at the end of the equilibration.

\section{Results}

\section{a) Synthesis and Hydrogelation}

Batches of Fmoc-RGDS and Fmoc-GRDS tetrapeptides were synthesized (Scheme 1) using standard techniques of solid-phase Fmoc peptide synthesis. Other batches of sample were purchased. The synthesis was performed on pre-loaded Wang resin (Fmoc-Ser( $t \mathrm{Bu})$-Wang resin) and Fmoc (9-fluorenylmethoxycarbonyl) protected amino acids, Fmoc-Arg(Pbf)-OH, Fmoc-Gly-OH, Fmoc Asp $(\mathrm{O} t \mathrm{Bu})-\mathrm{OH}$, with $t \mathrm{Bu}(t$ butyl) and Pbf (2,2,4,6,7-pentamethyldihydrobenzofuran-5-sulfonyl) as side chain protecting groups, which were removed during the course of the TFA-mediated 
cleavage. The obtained crude Fmoc tetrapeptides were purified by preparative reverse-phase HPLC. Fmoc-RGDS was found to form a self-supporting hydrogel at a concentration of $2 \mathrm{wt} \%$ in water. On the other hand, Fmoc-GRDS became highly viscous at this concentration it did not form a self-supporting hydrogel. The hydrogels are cloudy, which we associate with the presence of extended fibrils (vide infra). The dynamic mechanical properties of the hydrogels were probed in more detail by shear rheometry, as discussed shortly.

\section{b) Secondary Structure}

FTIR was also used to examine secondary structure, focussing on the amide I' region. Fig.1 shows spectra obtained for two concentrations of both Fmoc-RGDS and FmocGRDS. The 3 wt $\%$ Fmoc-GRDS sample shows features ascribed to $\beta$-sheets, i.e. a peak at $1630 \mathrm{~cm}^{-1}$. The peak at $1608 \mathrm{~cm}^{-1}$ is associated with the arginine side chain. ${ }^{42,}$ ${ }^{43}$ A peak at $1707 \mathrm{~cm}^{-1}$ is similar to those observed for Fmoc-RGD and Fmoc-GRD and is assigned to hydrogen bonded carbonyl units ${ }^{44}$ (in the D residue or at the $\mathrm{C}$ terminus), rather than a frequency-shifted peak arising from antiparallel $\beta$-sheets which are normally observed ${ }^{42,45,46}$ in the range $1680-1690 \mathrm{~cm}^{-1}$. It has to be noted that the assignment of a band in this range to antiparallel sheets has been the subject of debate in the literature\{Barth, $2002 \# 7021\}\{$ Torii, $2008 \# 8509\}$ although now commonly accepted.\{Kubelka, 2001 \#4372\}\{Barth, 2007 \#8162\} This spectrum and all others contain a strong peak at $1673 \mathrm{~cm}^{-1}$ which is assigned to TFA counterions ${ }^{46-}$ ${ }^{48}$ bound to $\mathrm{NH}_{3}{ }^{+}$groups (in the $\mathrm{R}$ residue). The spectrum for $3 \mathrm{wt} \%$ Fmoc-RGDS shows features of antiparallel $\beta$-sheets (peaks at $1638 \mathrm{~cm}^{-1}$ and $1698 \mathrm{~cm}^{-1}$ ) along with a broad peak in the range $1640-1655 \mathrm{~cm}^{-1}$ that are assigned to disordered structure. ${ }^{42}$

${ }^{49}$ Interestingly, the $1608 \mathrm{~cm}^{-1}$ arginine side chain peak is absent for this peptide, 
pointing possibly to salt bridging interactions (as supported by MD computer simulations, vide infra). At $1 \mathrm{wt} \%$, the spectrum in the amide I' region for FmocRGDS shows only a broad weak peak centered around $1645 \mathrm{~cm}^{-1}$ plus the TFA/ $\mathrm{NH}_{3}{ }^{+}$ peak. The spectrum for Fmoc-GRDS has the same features as the one for the $3 \mathrm{wt} \%$ sample. These results show that Fmoc-GRDS is able to form $\beta$-sheets for concentrations as low as $1 \mathrm{wt} \%$ in contrast to Fmoc-RGDS which mainly adopts a disordered conformation under these conditions. However, evidence from Congo red dye staining (vide infra), and cryo-TEM suggests at least the presence of some $\beta$-sheet amyloid fibrils at $1 \mathrm{wt} \%$ for this sample). These results are surprising in view of our previous findings on Fmoc-RGD and Fmoc-GRD, ${ }^{29}$ both of which show $\beta$-sheet features in the FTIR spectra at $3 \mathrm{wt} \%$, but not at $1 \mathrm{wt} \%$. It appears that the additional serine residue significantly reduces the aggregation tendency of Fmoc-RGDS, but has the opposite effect for Fmoc-GRDS.

In support of FTIR, UV circular dichroism spectroscopy was used to provide additional information on secondary structure. Fig. 2 shows spectra measured for 0.02 wt $\%$ and 1 wt $\%$ solutions. The spectra for these peptides are dominated by contributions from the Fmoc unit. The spectrum for Fmoc-GRDS contain a negative minimum at $218 \mathrm{~nm}$, as expected for a $\beta$-sheet structure, however the shape is not the typical broad minimum from $210-230$ with magnitude $-10,000$ to $-30,000 \mathrm{deg} \mathrm{cm}^{2}$ dmol $^{-1}$ expected. ${ }^{50}$ The spectrum for Fmoc-GRDS looks very much like the inverse of the spectrum for the fluorene moiety, ${ }^{51}$ while the spectrum for Fmoc-RGDS resembles that for a disordered or beta II turn conformation. ${ }^{50}$ The broad shoulder in the range $240-260 \mathrm{~nm}$ is due to the $\pi-\pi^{*}$ transition of the Fmoc group. ${ }^{6,52-54}$ This feature points to a chiral arrangement of Fmoc units ${ }^{9}$ and this may form the "backbone" for 
$\beta$-sheet fibrils, as discussed later when results from molecular dynamics computer simulations are presented. In contrast, the spectrum for Fmoc-RGDS shows a much lower signal (ellipticity) and, for the $1 \mathrm{wt} \%$ solution a broad minimum at around 222 nm. The spectrum for Fmoc-GRDS indicates stacking of Fmoc units in a chiral configuration.

These CD spectra show a difference in signal from the two peptides suggesting a difference in secondary structure. In order to ascertain that the signals were not from LD artifacts, the spectra for $0.02 \mathrm{wt} \%$ sample were measured with the sample oriented vertically (0 degrees) and horizontally (90 degrees). ${ }^{55}$ Down to around $200 \mathrm{~nm}$, the spectra were of similar shape for the two orientations indicating that these were true CD spectra. Further, the shapes do not follow that of the LD (see below). However, at wavelengths $<200 \mathrm{~nm}$ light scattering artefacts are prevalent and data should be treated with caution. This is because there is a non-linear inverse relationship between light scattering and wavelength.

To examine alignment effects in more detail, linear dichroism spectra were measured. LD spectra measured in the rectangular cuvettes (Fig 3a) showed a very small signal. This indicates that the molecules were not aligned macroscopically in these samples, consistent with the CD spectra in Fig. $2 b$ being correct. There is a dramatic difference in the spectra measured for the sample under shear in the Couette cell shown in Fig. $3 b$ where the Fmoc-GRDS peptide gives a large signal. The large signal shows that the molecules in this sample are both aligned and well ordered. There is considerable fine structure visible across the spectrum, in particular in the region from 240-320 $\mathrm{nm}$. The signals in this region arise from the Fmoc group ${ }^{6,9,53,56}$ and demonstrate that 
this part of the molecule is highly ordered. The sign of the LD absorbance from 245-260 nm indicates that the planar Fmoc unit is predominantly aligned perpendicular rather than parallel to the fibre axis, however the Fmoc absorbance at $240 \mathrm{~nm}$ is significant and the LD is positive so it must be tilted in some way.

At ten times higher peptide concentration, the LD spectra are similar (Fig. 4) to those shown in Fig.3b. This demonstrates that, at this concentration, the Fmoc-RGDS peptide does not form sufficiently ordered structures to align under these conditions. Note that the Fmoc-GRDS peptide does not give a significantly higher LD signal at $0.2 \mathrm{wt} \%$ than at $0.02 \mathrm{wt} \%$. This is perhaps surprising as the signal is proportional to concentration all other things being equal. It is possible that (a) the sample is harder to orient than the solution and/or (b) the shear in the Couette cell is disrupting the macromolecular structure.

To complement CD and FTIR, Congo red staining was performed for $1 \mathrm{wt} \%$ solutions of both samples, and green birefringence was observed by polarized optical microscopy (Fig.5). This is a diagnostic for amyloid fibril formation. ${ }^{57}$ This test reveals the presence of some amyloid fibrils (as also noted by cryo-TEM) for $1 \mathrm{wt} \%$ Fmoc-RGDS, although $\beta$-sheet features were not detectable by FTIR or CD at this concentration.

In summary, CD and FTIR spectroscopy show that the self-assembly of both FmocGRDS and Fmoc-RGDS is dominated by aromatic stacking interactions. Fmoc-GRDS probably forms some $\beta$-sheet structures for solutions containing as low as $1 \mathrm{wt} \%$ peptide, in contrast to Fmoc-GRDS. This is unanticipated in view of prior results for 
the corresponding Fmoc-tripeptides lacking a terminal serine residue and points to a strong influence of this residue on self-assembly.

\section{c) Fibril Superstructure - Cryo-TEM, SAXS and XRD}

Cryo-TEM was performed for both Fmoc-tetrapeptides at $1 \mathrm{wt} \%$ (the same concentration used for FTIR and CD experiments). Very few fibrils were observed for Fmoc-RGDS, consistent with the conclusions from CD and FTIR that this peptide has not substantially associated into $\beta$-sheets at this concentration. However, increasing the concentration to $2 \mathrm{wt} \%$ some more fibrils were observed (Fig.6a), although the coverage on the TEM grid was not high. In contrast, Fmoc-GRDS shows numerous well-defined twisted fibrils (Fig.6b) with a length of hundreds of nanometers, even at $1 \mathrm{wt} \%$.

SAXS results (Fig.7) for $2 \mathrm{wt} \%$ solutions of the Fmoc-tetrapeptides show strong form factor oscillations for both Fmoc-RGDS and Fmoc-GRDS. This points to the formation of well defined, relatively monodisperse, fibrils in solution for the Fmoctetrapeptides (Fig.7). The form factor was fitted to a cylinder form factor (using Porod's approximation for a long cylinder ${ }^{58}$ ) with a radius $R=4.9 \mathrm{~nm}$ (Gaussian polydispersity $\sigma=15 \%)$ for Fmoc-GRDS and $R=4.1 \mathrm{~nm}(\sigma=20 \%)$ for FmocRGDS. Other parameters were the cylinder length $L=5000 \mathrm{~nm}$ for both samples and an intensity scale factor. A flat background was incorporated in the fit model. This form factor describes the data very well. In addition to the form factor oscillations, a peak is observed at $q=(2.3 \pm 0.05) \mathrm{nm}^{-1}$ for Fmoc-GRDS and $q=(1.88 \pm 0.04) \mathrm{nm}^{-1}$ for Fmoc-RGDS corresponding, respectively, to spacings $d=(2.7 \pm 0.4) \mathrm{nm}$ and $d=$ 
$(3.34 \pm 0.07) \mathrm{nm}$. These spacings are associated with the longitudinal ordering of the Fmoc-tetrapeptides molecules. This was confirmed by X-ray diffraction on dried stalks (to be discussed shortly). The peak for Fmoc-RGDS has a significantly larger spacing than for Fmoc-GRDS.

X-ray diffraction patterns obtained for dried stalks (dried fibres with a sub-mm diameter) are presented in Fig. 8. The patterns show different extents of orientation however features of a "cross-beta" $\mathrm{x}$-ray diffraction are present for both, i.e. there is a series of reflections with enhanced intensity on the equator at low angle and a series of strong meridional reflections (with a primary peak at $4.5-4.7 \AA$ ) at higher angle. For Fmoc-RGDS, the first equatorial reflection corresponds to a spacing $d=2.52 \mathrm{~nm}$. This is smaller than the spacing of the Bragg peak observed in the SAXS pattern, however the positions of the peaks in the SAXS profiles are certainly affected by cylinder form factor oscillations. For Fmoc-GRDS the corresponding spacing is $d=$ $31.9 \pm 0.2$, in good agreement with the value from SAXS. The fact that these are equatorial reflections indicates that this spacing is perpendicular to the fibril axis. As it is not related to the $1-1.2 \mathrm{~nm} \beta$-sheet stacking spacing observed in the "cross-beta" pattern for amyloid fibrils, we associate it with the structure within the $\beta$-sheets. Specifically, this is assigned to the ordering of the long axis of Fmoc-RGDS molecules. The length of a tetrapeptide in a parallel $\beta$-sheet is approximately ${ }^{60} 4 \times$ $0.32 \mathrm{~nm}=1.28 \mathrm{~nm}$. It is likely that the Fmoc units are overlapped (as indicated by the chiral CD signal from Fmoc units), giving rise to an antiparallel $\beta$-sheet structure with interdigitated Fmoc units. Similar models have been proposed by Ulijn et al. for the self-assembled nanotube structure of Fmoc-LLL ${ }^{61}$ and Fmoc-FF. ${ }^{54}$ In the latter case, a spacing of $2.6 \mathrm{~nm}$ was associated with the width of the fibrils. For Fmoc-LLL, 
the outer diameter of the tubes was $2.4 \mathrm{~nm}$. The spacings reported in Table 1 for Fmoc-RGDS differ substantially from those previously reported for Fmoc-RGD, ${ }^{29}$ indicating that the arrangement of $\beta$-sheets is very sensitive to peptide sequence. In contrast, the spacings for Fmoc-GRD ${ }^{29}$ and Fmoc-GRDS are in closer agreement. The long spacings obtained from fibre XRD on dried stalks are in general in good agreement with the values from in situ SAXS on solutions detailed above, and this provides confidence that the fibre XRD patterns reflect the $\beta$-sheet structure in solution.

\section{d) Rheology}

Attempts were made to measure the dynamic shear moduli of hydrogels formed by the two Fmoc-tetrapeptides in 2 wt $\%$ aqueous solutions. The gel of Fmoc-RGDS although extremely stiff (apparent values of $G^{\prime}$ in the range $10^{5}-10^{6} \mathrm{~Pa}$ were found in controlled strain experiments at low strain $0.008-0.02 \%$ ) was found to undergo significant syneresis when subjected even to very low stresses or strains. Therefore reliable dynamic moduli values could not be obtained. In contrast, although the gel of Fmoc-GRDS was much weaker, reliable shear rheometry experiments could be performed. Fig.9 shows frequency sweep data (obtained at a low stress $\sigma=0.2 \mathrm{~Pa}$, to ensure a viscoelastic response in the linear regime). At low frequency, $G^{\prime}>G^{\prime \prime}$ and the low values of the modulus are consistent with the formation of a weak hydrogel. It can be noted that that the values of $G^{\prime}$ for this hydrogel are smaller than the values reported for the Fmoc-GRD homologue. ${ }^{29}$ for which $G^{\prime}$ exceeded $10^{4} \mathrm{~Pa}$ over the frequency range measured (in controlled strain experiments at low strains $<0.1 \%$ in the linear viscoelastic regime). For the tripeptides, it was also noted that the dynamic 
elastic modulus was larger for the 2 wt $\%$ Fmoc-RGD gel than the 2 wt $\%$ Fmoc-GRD gel.

\section{e) Molecular Dynamics Computer Simulations}

In order to examine the stability of different configurations of Fmoc-RGDS and Fmoc-GRDS molecular dynamics computer simulations in aqueous solution were performed using models with $n=7$ or $n=21$ explicit peptide molecules in parallel or antiparallel configurations. Figure 10 shows the starting structures for the four simulations with $n=21$ explicit peptide molecules. After the MD run, intermolecular distance distributions were calculated and the internal energies of parallel and antiparallel configurations of both molecules were compared.

Table 2 compares the average intermolecular distance between two consecutive peptide molecules for the p/Fmoc-RGDS, a/Fmoc-RGDS, p/Fmoc-GRDS and a/Fmoc-GRDS systems. Distances were calculated considering the centre of mass of each peptide and averaging over the last half of each MD productive trajectory (i.e. the last 10 and $5 \mathrm{~ns}$ for systems simulated with 7 and 21 peptide molecules, respectively). As can be seen, simulations with 7 and 21 peptide molecules led to very similar results. The p/Fmoc-RGDS assembly retains the initial intermolecular distance at $\sim 4.7 \AA$ while the a/Fmoc-RGDS breaks down into small assemblies, evidencing the lower stability of this disposition. Thus, the intermolecular distance is $\sim 2.6$ and $\sim 1.5$ $\AA$ larger for the antiparallel assembly than for the parallel one in simulations with 7 and 21 peptide molecules, respectively. Similarly, the intermolecular distance between neighboring chains is smaller for the p/Fmoc-GRDS than for the a/Fmoc- 
GRDS, even though in this case the difference increases to $8 \AA$, independently of the number of peptide molecules. This result indicates that Fmoc-GRDS prefers the parallel assembly. There is also a significant difference between p/Fmoc-RGDS and p/Fmoc-GRDS in that the intermolecular distance is 0.9 and $1.9 \AA$ larger for the latter than for the former in simulations with 7 and 21 peptide molecules, respectively, which reflects the higher tendency of the Fmoc-RGDS peptide to form assemblies. The final snapshot of the p/Fmoc-RGDS simulation with 21 peptide molecules is depicted in Figure 10b.

On the other hand, analysis of the p/Fmoc-GRDS systems at the end of the MD simulations indicates that the initial arrangements, in which neighbouring peptides were located at the identical intermolecular distances defining a unique assembly (Figure 10a), transformed into aggregates of smaller assemblies. More specifically, the system involving 21 peptide chains transformed into four assemblies, each one being constituted by $4-7$ peptide molecules separated by $\sim 4.7 \AA$. These assemblies tend to aggregate, as is reflected by the shortest distance between the centre of mass of two peptides belonging to different but neighboring assemblies, which range between 5.5 and $6.2 \AA$. This is an important difference with respect to p/Fmoc-RGDS, in which the 21 peptide molecules remained within the initial assembly (Figure 10b). Thus, although the Fmoc-RGDS peptide is able to stabilize assemblies involving a large number of molecules through salt bridges networks (see below), the dimensions of the assemblies involving Fmoc-GRDS is limited by the formation of weaker hydrogen bonds. A complete analysis of the interactions involved in both p/FmocRGDS and p/Fmoc-GRDS is provided below. 
Figure 11a displays the probability distribution functions for the average intermolecular distances between neighboring chains of the systems simulated with both 7 and 21 peptide molecules, which were determined using the snapshots recording during the whole trajectories. As can be seen, the p/Fmoc-RGDS shows a sharp peak centered at $\sim 4.7 \AA$, which is particularly pronounced for the simulation with 21 molecules. This peak is in excellent agreement with experimental observations. Sharp peaks at $\sim 4.2$ and $\sim 5.3 \AA$ are also detected for the p/Fmoc-GRDS with 7 peptide molecules, whereas these peaks merge and shift towards $\sim 7.1 \AA$ in the simulation with 21 peptides. These values are also broadly consistent with spacings obtained from XRD displayed in Table 1. These results also indicate that FmocRGDS tends to stabilize large assemblies while Fmoc-GRDS organizations involve a smaller number of molecules.

Figure $11 \mathrm{~b}$ compares the averaged total internal energies per peptide molecule for the four investigated systems, as well as their corresponding van der Waals and electrostatic contributions (i.e. the difference between the total energy and the sum of the van der Waals and electrostatic contributions corresponds to the bonding component, which is not explicitly displayed). It is worth noting that, independent of the number of peptide molecules, the relative variation of the total internal energies follows the same trends that the electrostatic component, indicating that the stabilization of the four systems is essentially due to the participation of inter- and intramolecular interactions that involve polar atoms (i.e. charged and polar side groups, and peptide bonds). 
Interestingly, the p/Fmoc-RGDS is the least stable system for both simulations with 7 and 21 peptide molecules. This can be attributed to the fact that, in spite of its tightness, this self-assembly is mainly stabilized through salt bridges between the Arg and Asp side chains of residues located at the same molecule (intramolecular interactions) or at consecutive molecules (intermolecular interactions), rather than by intermolecular hydrogen bonds typically associated to the $\beta$ sheets (Figure $10 \mathrm{~b}$ ). This conclusion is supported by the FTIR spectra shown in Fig. 1. The simulations reveal that, in terms of population, such intra- and inter- molecular salt bridges show occurrences of $\sim 28 \%$ and $\sim 53 \%$, respectively. The importance of salt bridges is considerably lower for the other three investigated systems (i.e. occurrences are lower than $7 \%$ and $38 \%$ for intra- and intermolecular Arg-Asp salt bridges). On the other hand, the p/Fmoc-GRDS system is essentially stabilized through backbone $\cdots$ backbone intermolecular hydrogen bonds, even though the participation of inter- and intramolecular interactions between the side groups of Arg and Ser is not negligible (i.e. $25 \%$ and $20 \%$, respectively).

\section{Summary and Discussion}

Both Fmoc-RGDS and Fmoc-GRDS fibrillise under appropriate conditions. The selfassembly at low concentration is driven by interactions between Fmoc units which produces many features in the CD spectra. Unexpectedly, the scrambled "control" peptide Fmoc-GRDS actually self-assembles more readily than Fmoc-RGDS. In addition, strong alignment of this peptide occurs under shear, even in dilute solution leading to significant linear dichroism. This system is promising for the development of aligned biomolecular substrates. The use of either Fmoc-RGDS or Fmoc-GRDS within collagen-based substrates for cell growth applications is the subject of ongoing 
research in our labs. ${ }^{62}$ It is possible that the reduced tendency for Fmoc-RGDS to form amyloid fibrils may result in reduced toxicity to cells and hence enhanced bioactivity. This is presently being investigated further.

The observations from XRD that, at sufficiently high concentration, Fmoc-RGDS forms antiparallel $\beta$-sheets is in conflict with the model proposed by Nilsson and coworkers for Fmoc-F derivatives containing fluorinated phenylalanine residues. ${ }^{63,64}$ They propose that stacking of Fmoc residues and exposure of the carboxyl termini favours a parallel configuration. This model is distinct from that put forward by Uljin et al. for Fmoc- $\mathrm{FF}^{54}$ and by ourselves for Fmoc- $\beta \mathrm{AH}$ (Fmoc- $\beta$-alanine-histidine) ${ }^{65}$ based on antiparallel stacking, as confirmed by the presence of a peak in the amide I' FTIR spectrum in the $1680-1690 \mathrm{~cm}^{-1}$ range. On the other hand, XRD data and FTIR spectra for Fmoc-RGDS do not provide clear cut information on a parallel vs. antiparallel of the $\beta$-sheets, but MD simulations seem to indicate a preferred parallel $\beta$-sheet configuration. It appears that the $\beta$-sheet arrangement of short Fmoc peptides depends on peptide length and/or sequence.

MD computer simulations suggest that Fmoc-RGDS may self-assemble into an antiparallel configuration, since the parallel configuration was found to be less stable as salt bridging was found to play a significant role in this case. This finding is in agreement with the experimental results. In contrast, Fmoc-GRDS forms more stable assemblies than $\mathrm{p} / \mathrm{Fmoc}-\mathrm{RGDS}$ in either parallel or antiparallel configurations due to $\beta$-sheet intermolecular hydrogen bonding interactions. The simulations favour the parallel configuration of Fmoc-GRDS $\beta$-sheets, in contrast to Fmoc-RGDS. This is 
on the basis of the internal energy calculations, as well as the intermolecular distance distributions (the spacing for a/Fmoc-GRDS is too large).

Gazit and coworkers showed that the Fmoc-tetrapeptides Fmoc-RGDF and FmocFRGD both form hydrogels containing $\beta$-sheet hydrogels. ${ }^{66}$ It may be noted that $\mathrm{F}$ is much more hydrophobic than the serine residue used in our Fmoc-RGDS peptide. In addition, Gazit's "scrambled" peptide differs in sequence from Fmoc-GRDS, since in both of our peptides the terminal serine functionality is retained.

Applications of collagen-based materials in biomedical applications including tissue growth have been reviewed. ${ }^{67,68}$ In future work, we plan to use the two Fmoctetrapeptides to produce collagen-based gels that can be used to grow corneal fibroblasts. ${ }^{62}$ These biomaterials offer the potential advantage that the collagen gels can now be functionalised. i.e. they combine the best of both worlds, the tissue-like mechanical properties of compressed collagen gels with the chemical functionality of functionalized tetrapeptides.

Acknowledgements. This work was supported by EPSRC grants EP/F048114/1 and EP/G026203/1 to IWH. We are grateful to Steve Furzeland and Derek Atkins (Unilever, Colworth, UK) for the cryo-TEM experiments. Use of the Chemical Analysis Facility at the University of Reading is acknowledged. We are grateful to Dr Jeremie Gummel for assistance with SAXS experiments at the ESRF (beamtime ref. SC2985). Work at Warwick was supported by grants EPSRC EP/F500378/1 and BBSRC BB/F011199/1. Work in Barcelona was funded by grants MAT2009-09138 
and 2009SGR1208. Support for the research of C.A. was received through the prize "ICREA Academia" for excellence in research funded by the Generalitat de Catalunya. 


\section{References}

X. B. Zhao, F. Pan, H. Xu, M. Yaseen, H. H. Shan, C. A. E. Hauser, S. G.

Zhang, and J. R. Lu, Chem. Soc. Rev., 2010, 39, 3480.

2

S. S. Santoso, S. Vauthey, and S. Zhang, Curr. Opin. Colloid Interface Sci., 2002, 7, 262.

3 S. G. Zhang, Nature Biotechnology, 2003, 21, 1171.

$4 \quad$ X. Zhao and S. Zhang, Trends in Biotechnology, 2004, 22, 470.

$5 \quad$ I. W. Hamley Soft Matter, 2011, 7, 4122.

6

Z. Yang and B. Xu, Chem. Comm., 2004, 2424.

7 Z. Yang, G. Liang, M. Ma, Y. Gao, and B. Xu, J. Mater. Chem., 2007, 17, 850.

S. Toledano, R. J. Williams, V. Jayawarna, and R. V. Ulijn, J. Am. Chem. Soc., 2006, 128, 1070

9

V. Jayawarna, M. Ali, T. A. Jowitt, A. F. Miller, A. Saiani, J. E. Gough, and R. V. Ulijn, Adv. Mater., 2006, 18, 611.

V. Jayawarna, S. M. Richardson, A. R. Hirst, N. W. Hodson, A. Saiani, J. E. Gough, and R. V. Ulijn, Acta Biomater., 2009, 5, 934.

M. Zhou, A. M. Smith, A. K. Das, N. W. Hodson, R. F. Collins, R. V. Ulijn, and J. E. Gough, Biomaterials, 2009, 30, 2523.

R. J. Mart, R. D. Osborne, M. M. Stevens, and R. V. Ulijn, Soft Matter, 2006, 2,822 .

A. Mahler, M. Reches, M. Rechter, S. Cohen, and E. Gazit, Adv. Mater., 2006, 18, 1365.

14

D. J. Adams, M. F. Butler, W. J. Frith, M. Kirkland, L. Mullen, and P.

Sanderson, Soft Matter, 2009, 5, 1856. 
E. Ruoslahti and M. D. Pierschbacher, Science, 1987, 238, 491. 582.

J. A. Hubbell, Bio-Technology, 1995, 13, 565.

M. Tirrell, E. Kokkoli, and M. Biesalski, Surf. Sci., 2002, 500, 61.

M. D. Mager, V. LaPointe, and M. M. Stevens, Nature Chemistry, 2011, 3,

J. Samanen, F. Ali, T. Romoff, R. Calvo, E. Sorenson, J. Vasko, B. Storer, D.

Berry, D. Bennett, M. Strohsacker, D. Powers, J. Stadel, and A. Nichols, J. Med. Chem., 1991, 34, 3114.

L. Alig, A. Edenhofer, P. Hadvary, M. Hurzeler, D. Knopp, M. Muller, B.

Steiner, A. Trzeciak, and T. Weller, J. Med. Chem., 1992, 35, 4393.

M. O. Guler, L. Hsu, S. Soukasene, D. A. Harrington, J. F. Hulvat, and S. I.

Stupp, Biomacromolecules, 2006, 7, 1855.

T. Muraoka, C.-Y. Koh, H. Cui, and S. I. Stupp, Angew. Chem., Int. Ed. Engl., 2009, 38, 5946.

M. J. Webber, J. Tongers, M.-A. Renault, J. G. Roncalli, D. W. Losordo, and

S. I. Stupp, Acta Biomater., 2010, 6, 3.

Y. Jin, X.-D. Xu, C.-S. Chen, S.-X. Cheng, X.-Z. Zhang, and R.-X. Zhuo, Macromol.Rapid Comm., 2009, 29, 1726.

U. Hersel, C. Dahmen, and H. Kessler, Biomaterials, 2003, 24, 4385.

E. L. Bakota, Y. Wang, F. R. Danesh, and J. D. Hartgerink, Biomacromolecules, 2011, 12, 1651.

S. L. Gras, A. K. Tickler, A. M. Squires, G. L. Devlin, M. A. Horton, C. M. Dobson, and C. MacPhee, Biomaterials, 2008, 29, 1553. 

Matter, 2011, 7, 1326.

M. D. Pierschbacher and E. Ruoslahti, Nature (London), 1984, 309, 30.

M. D. Pierschbacher and E. Ruoslahti, J. Biol. Chem., 1987, 262, 17294.

Y. Hirano, M. Okuno, T. Hayashi, K. Goto, and A. Nakajima, J. Biomater. Sci.-Polym. Ed., 1993, 4, 235.

R. Marrington, T. R. Dafforn, D. J. Halsall, and A. Rodger, Biophys. J., 2004, 87, 2002.

R. Marrington, T. R. Dafforn, D. J. Halsall, J. I. MacDonald, M. Hicks, and A. Rodger, Analyst, 2005, 130, 1608.

Y. Duan, C. Wu, S. Chowdhury, M. C. Lee, G. M. Xiong, W. Zhang, R. Yang, P. Cieplak, R. Luo, T. Lee, J. Caldwell, J. M. Wang, and P. Kollman, J. Comput. Chem., 2003, 24, 1999.

W. D. Cornell, P. Cieplak, C. I. Bayly, I. R. Gould, K. M. Merz, D. M.

Ferguson, D. C. Spellmeyer, T. Fox, J. W. Caldwell, and P. A. Kollman, J. Am. Chem. Soc., 1995, 117, 5179.

T. Darden, D. York, and L. Pedersen, J. Chem. Phys., 1993, 98, 10089. H. J. C. Berendsen, J. P. M. Postma, W. F. Vangunsteren, A. Dinola, and J. R. Haak, J. Chem. Phys., 1984, 81, 3684.

J. P. Ryckaert, G. Ciccotti, and H. J. C. Berendsen, J. Comput. Phys., 1977, 23, 327 .

J. C. Phillips, R. Braun, W. Wang, J. Gumbart, E. Tajkhorshid, E. Villa, C. Chipot, R. D. Skeel, L. Kale, and K. Schulten, J. Comput. Chem., 2005, 26, 1781. 

Klein, J. Chem. Phys., 1983, 79, 926.

A. Barth, Biochim. Biophys. Acta-Bioenerg., 2007, 1767, 1073.

A. Barth and C. Zscherp, Q. Rev. Biophys., 2002, 35, 369.

L. J. Bellamy, 'The infra-red spectra of complex molecules', Chapman and Hall, 1975.

S. Krimm and J. Bandekar, Adv. Protein Chem., 1986, 38, 181.

P. Haris and D. Chapman, Biopolymers, 1995, 37, 251.

H. Gaussier, H. Morency, M. C. Lavoie, and M. Subirade, Appl. Environ. Microbiol., 2002, 68, 4803.

J. T. Pelton and L. R. McLean, Anal. Biochem., 2000, 277, 167.

B. Stuart, 'Biological Applications of Infrared Spectroscopy', Wiley, 1997.

R. W. Woody, in 'Circular dichroism of peptides and proteins', ed. K.

Nakanishi, N. Berova, and R. W. Woody, New York, 1994.

W. V. Mayneord and E. M. F. Roe, Proceedings of the Royal Society

(London), Series A, 1937, 158, 634.

Z. Yang, H. Gu, D. Fu, P. Gao, J. K. W. Lam, and B. Xu, Adv. Mater., 2004, 16, 1440.

Y. Zhang, H. Gu, Z. Yang, and B. Xu, J. Am. Chem. Soc., 2003, 125, 13680.

A. M. Smith, R. J. Williams, C. Tang, P. Coppo, R. F. Collins, M. L. Turner, A. Saiani, and R. V. Ulijn, Adv. Mater., 2008, 20, 37.

M. R. Hicks, J. Kowalski, and A. Rodger, Chem. Soc. Rev., 2010, 39, 3380.

D. M. Ryan, S. B. Anderson, and B. L. Nilsson, Soft Matter, 2010, 6, 3220.

I. W. Hamley Angew. Chem., Int. Ed. Engl., 2007, 46, 8128.

J. Kohlbrecher, in 'http://kur.web.psi.ch/sans1/SANSSoft/sasfit.html', 2009. 

Langmuir, 2010, 26, 4990.

T. E. Creighton, 'Proteins. Structures and Molecular Properties', W.H.Freeman, 1993. H. Xu, A. K. Das, M. Horie, M. S. Shaik, A. M. Smith, Y. Luo, X. Lu, R. Collins, S. Y. Liem, A. Song, P. L. A. Popelier, M. L. Turner, P. Xiao, I. A. Kinloch, and R. V. Ulijn, Nanoscale, 2010, 2, 960. R. R. Jones, V. Castelletto, C. J. Connon, and I. W. Hamley in preparation, 2011.

D. M. Ryan, T. M. Doran, and B. L. Nilsson, Chem. Comm., 2011, 47, 475. D. M. Ryan, T. M. Doran, S. B. Anderson, and B. L. Nilsson, Langmuir, 2011, 27, 4029.

V. Castelletto, G. Cheng, B. W. Greenland, and I. W. Hamley, Langmuir, 2011, 27, 2980.

R. Orbach, L. Adler-Abramovich, S. Zigerson, I. Mironi-Harpaz, D. Seliktar, and E. Gazit, Biomacromolecules, 2009, 10, 2646.

67 C. H. Lee, A. Singla, and Y. Lee, Int. J. Pharm., 2001, $221,1$. $12,1387$. 
Table 1. Spacings (in $\AA$ ) from X-ray diffraction patterns

\begin{tabular}{|ll|}
\hline $\begin{array}{l}\text { Fmoc-RGDS }( \pm 0.02, \\
\text { unless stated })\end{array}$ & $\begin{array}{l}\text { Fmoc-GRDS }( \pm 0.02, \\
\text { unless stated })\end{array}$ \\
\hline $25.6 \pm 0.2(\mathrm{e})$ & $31.9 \pm 0.2(\mathrm{e})$ \\
\hline & $16.1 \pm 0.1(\mathrm{e})$ \\
\hline $11.6 \pm 0.1(\mathrm{e})$ & $12.8 \pm 0.1(\mathrm{e})$ \\
\hline & $10.09(\mathrm{e})$ \\
\hline $9.92(\mathrm{e})$ & $9.26(\mathrm{e})$ \\
\hline $7.78(\mathrm{e})$ & \\
\hline $6.76(\mathrm{e})$ & $6.29(\mathrm{e})$ \\
\hline & $5.50(\mathrm{e})$ \\
\hline $4.48^{*}(\mathrm{~m})$ & $4.69 *(\mathrm{~m})$ \\
\hline $3.86(\mathrm{~m})$ & $3.86(\mathrm{~m})$ \\
\hline & $4.17(\mathrm{~m})$ \\
\hline $3.55(\mathrm{~m})$ & $3.46(\mathrm{~m})$ \\
\hline
\end{tabular}

Key. e: Equatorial, m: meridional, i: isotropic, * primary meridional reflection

Table 2. Average intermolecular distances, calculated from MD simulations, considering the centers of masses of consecutive molecules, for systems with 7 or 21 peptides. Data is expressed as an average in $\AA \pm 2$ times the standard deviation.

\begin{tabular}{ccccc}
\hline & $\mathrm{p} /$ Fmoc-RGDS & $\mathrm{a} /$ Fmoc-RGDS & $\mathrm{p} /$ Fmoc-GRDS & $\mathrm{a} /$ Fmoc-GRDS \\
\hline 7 molecules & $4.72 \pm 0.53$ & $7.28 \pm 2.35$ & $5.62 \pm 2.23$ & $13.57 \pm 4.66$ \\
21 molecules & $4.67 \pm 0.63$ & $6.19 \pm 2.64$ & $6.61 \pm 2.82$ & $14.70 \pm 4.56$ \\
\hline
\end{tabular}




\section{Figures}

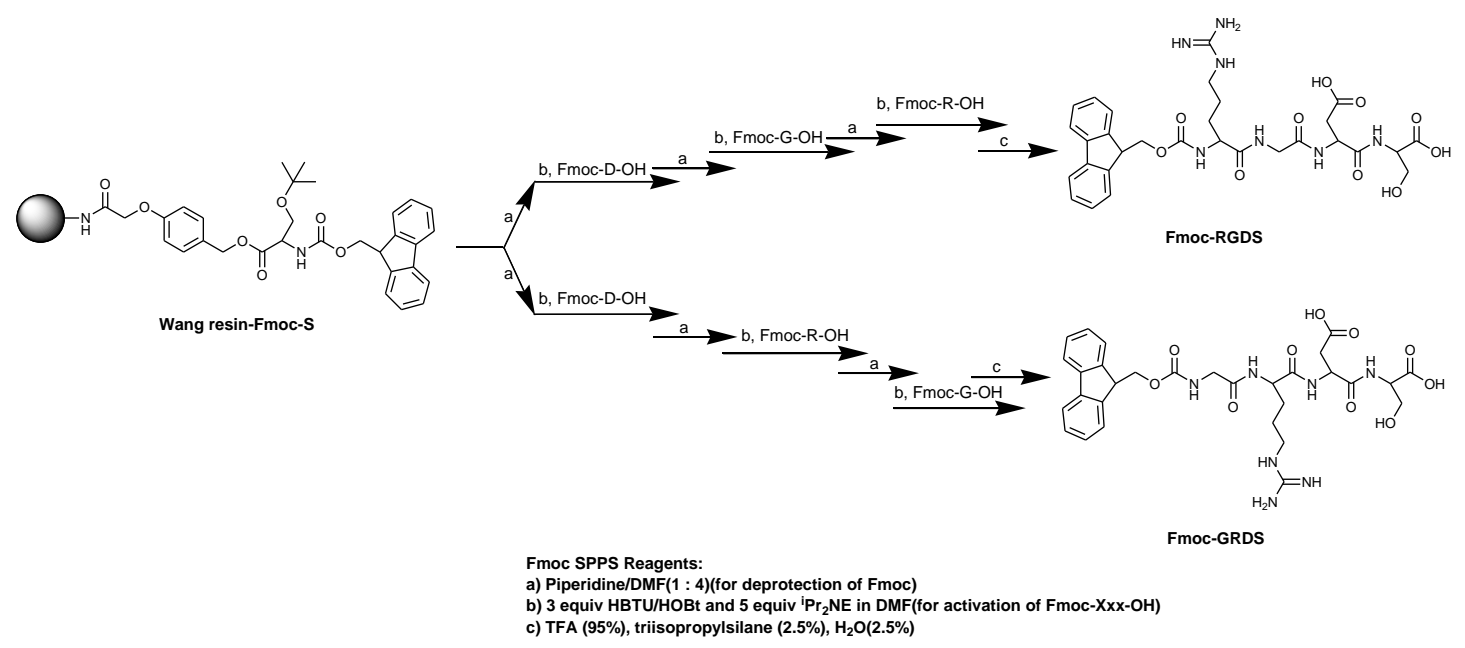

Scheme 1. Synthesis of Fmoc-Tetrapeptides Fmoc-RGDS and Fmoc-GRDS. Solid phase peptide synthesis reagents: a) Piperidine/DMF(1:4); b) 3 equiv HBTU/HOBt and 5 equiv ${ }^{\mathrm{i}} \mathrm{Pr}_{2} \mathrm{NE}$ in DMF; c) TFA (95\%), triisopropylsilane $(2.5 \%), \mathrm{H}_{2} \mathrm{O}(2.5 \%)$. 


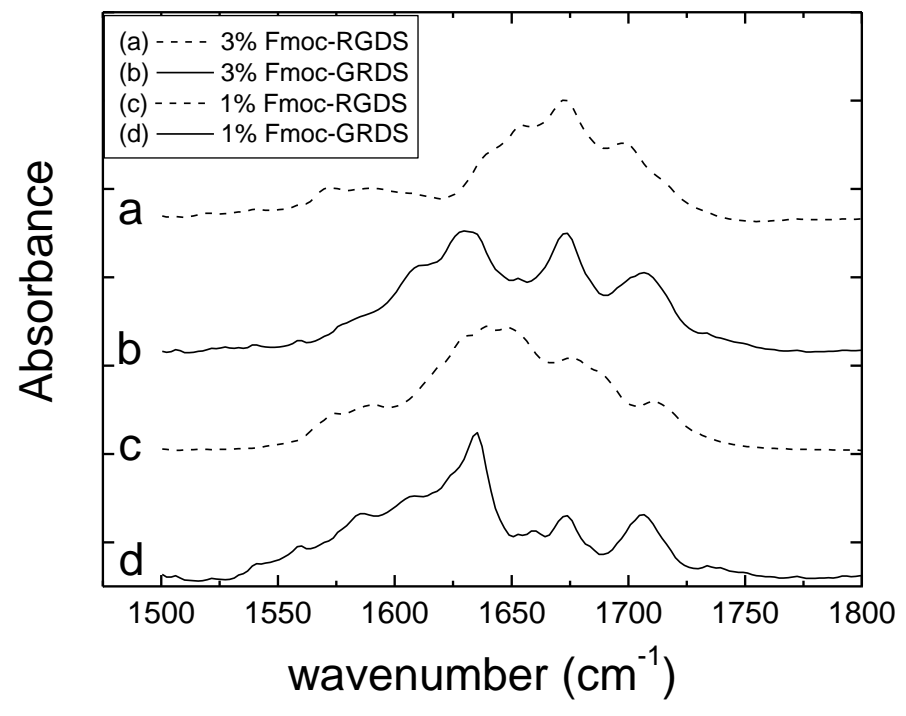

Fig.1. FTIR spectra of Fmoc-RGDS and Fmoc-GRDS measured for $1 \mathrm{wt} \%$ and 3 wt $\%$ solutions in $\mathrm{D}_{2} \mathrm{O}$. Spectra are shifted vertically for convenience. 

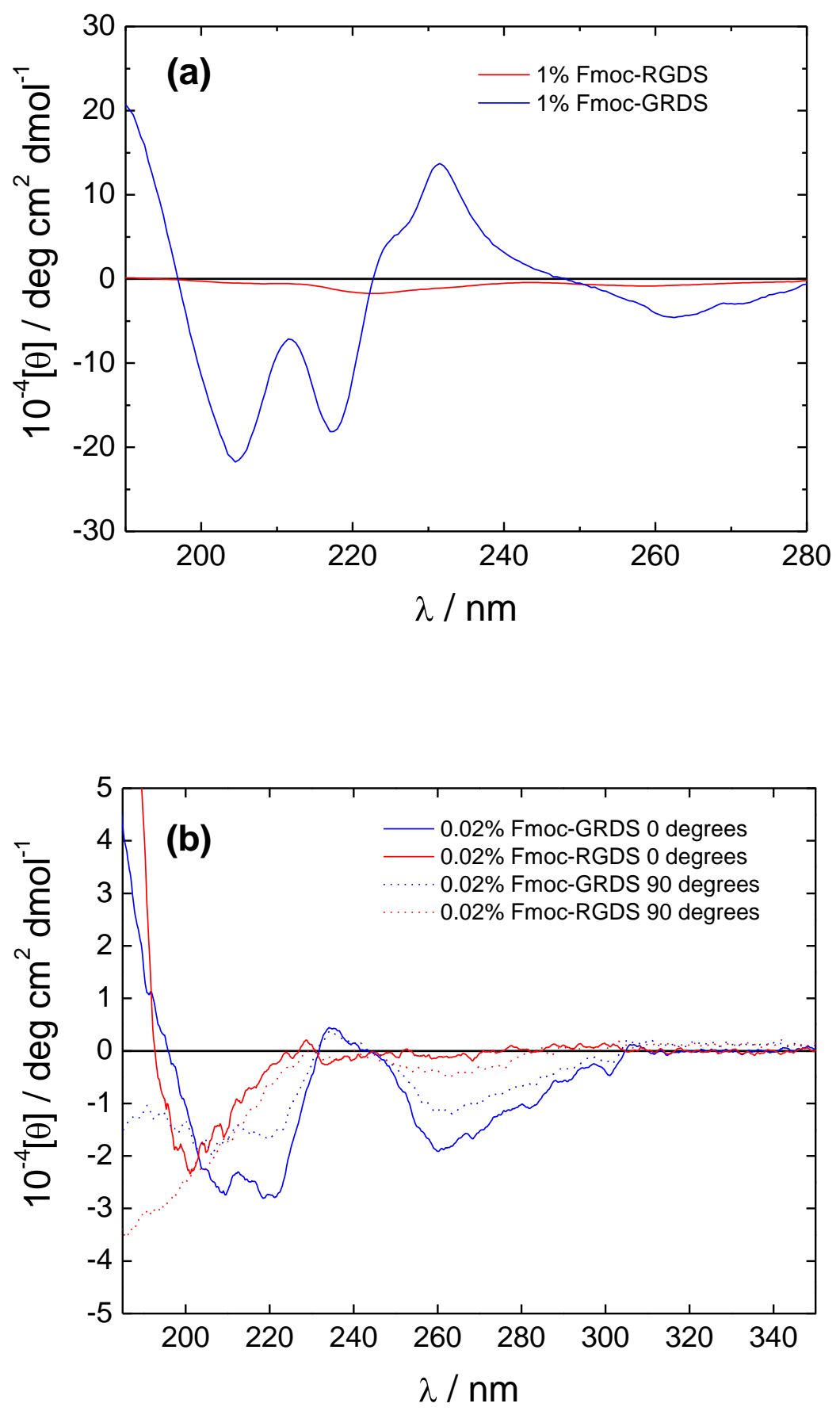

Fig.2. CD spectra for solutions of the two Fmoc-tetrapeptides (a) $1 \mathrm{wt} \%$, (b) 0.02 wt $\%$. The spectra in (a) were recorded on a Chirascan spectrometer with the cuvette in the usual vertical configuration, while those in (b) were recorded on a Jasci J-815 spectrometer with a modified cell holder, enabling sample rotation. 

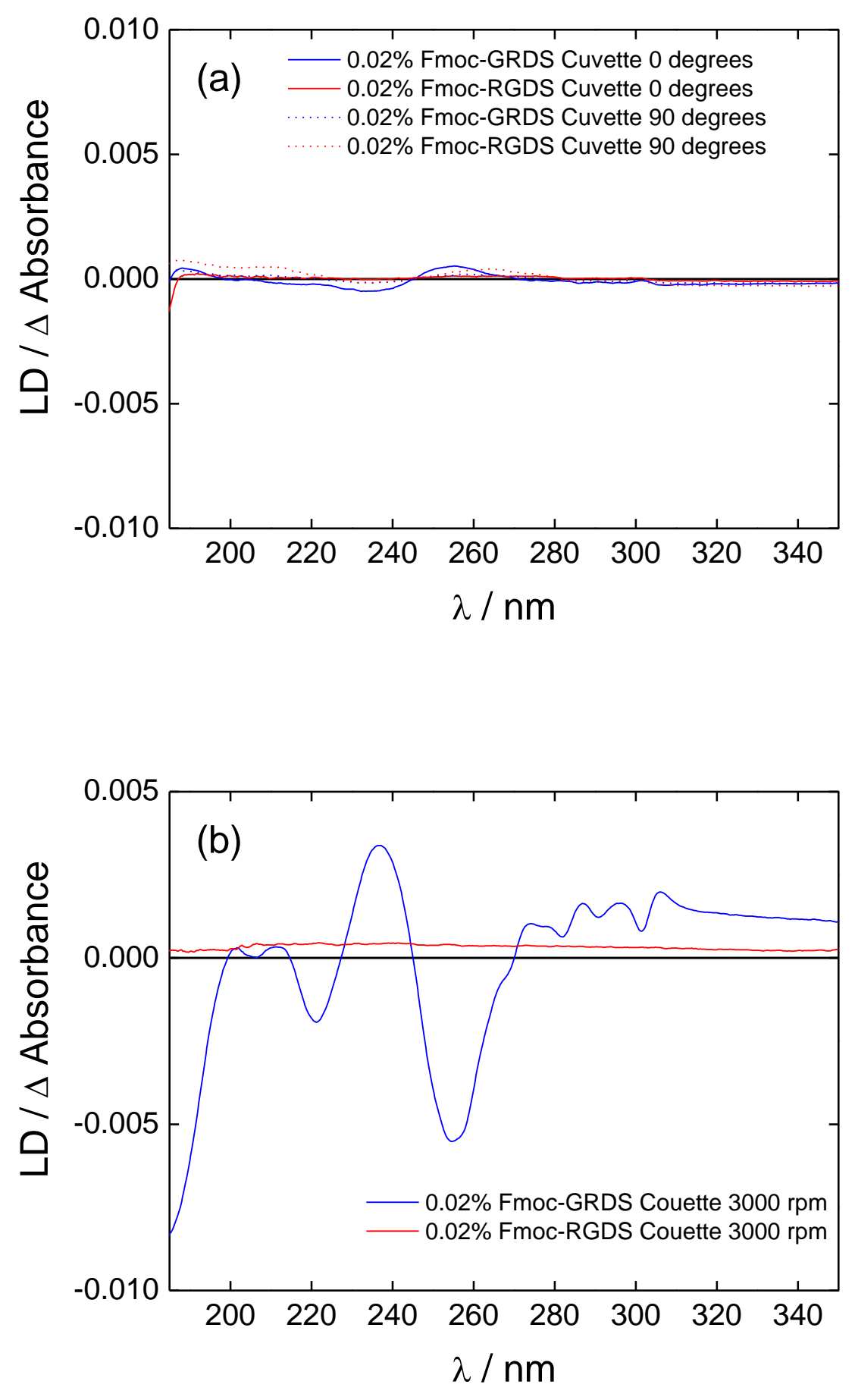

Fig.3. LD spectra of Fmoc-GRDS and Fmoc-RGDS peptides in water at $0.02 \mathrm{wt} \%$. Samples were placed in a) in a rectangular $1 \mathrm{~mm}$ path length cell, the same as for CD measurements in Fig. $2 b$ and b) in a $0.5 \mathrm{~mm}$ path length Couette alignment cell. 


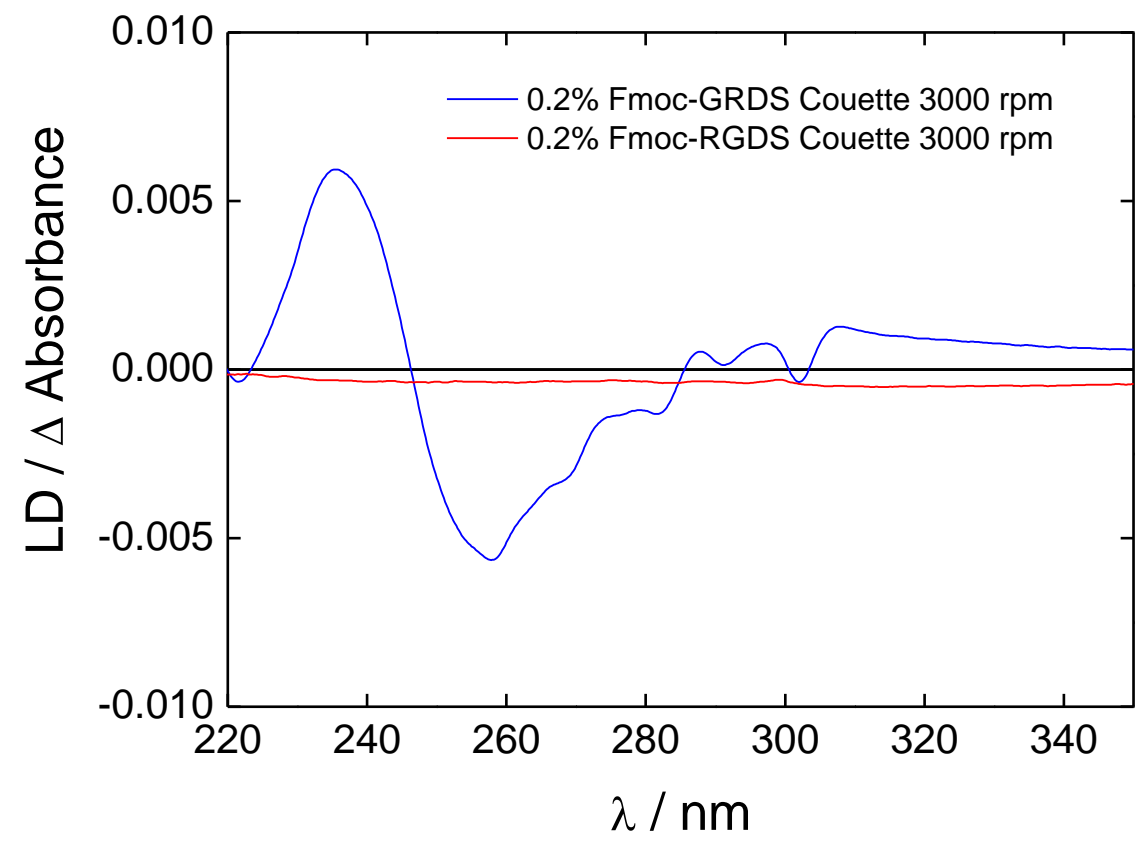

Fig. 4. LD spectra of Fmoc-GRDS and Fmoc-RGDS peptides in water at $0.2 \mathrm{wt} \%$ in a $0.5 \mathrm{~mm}$ path length Couette alignment cell. 

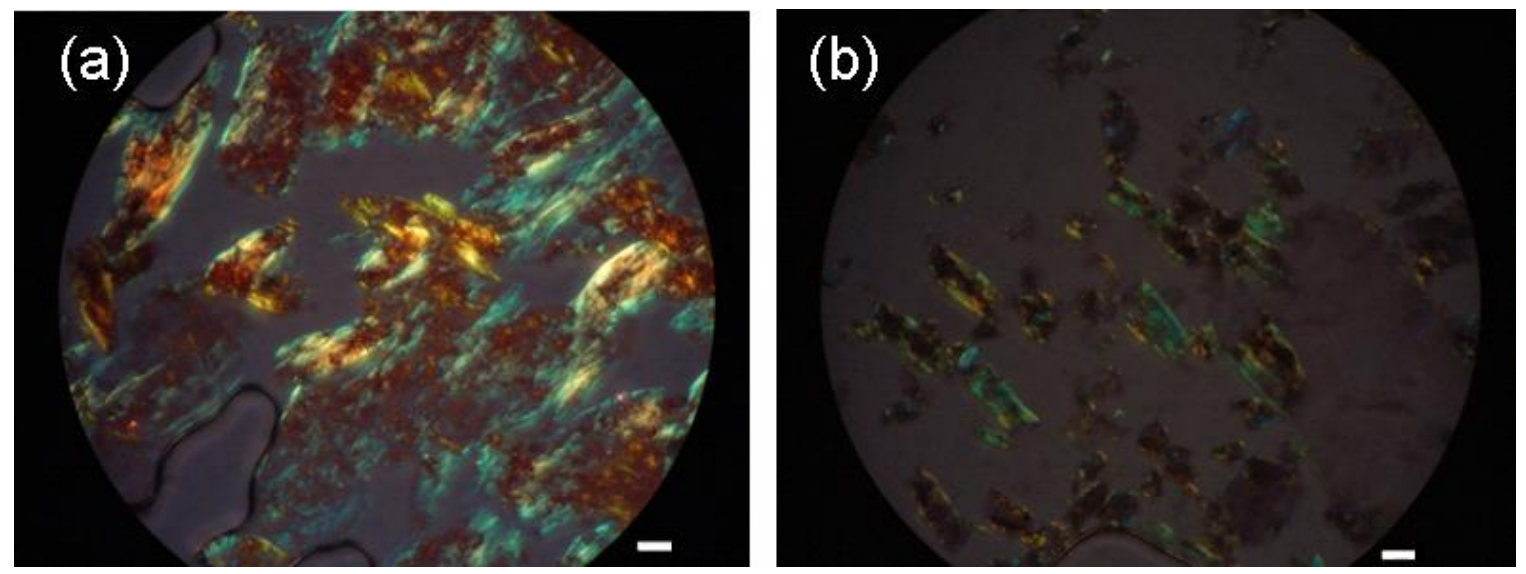

Fig.5. Polarized optical microscope images of Congo red stained solutions (1 wt $\%$ peptide) of (a) Fmoc-RGDS, (b) Fmoc-GRDS. The scale bars represent $100 \mu \mathrm{m}$. 

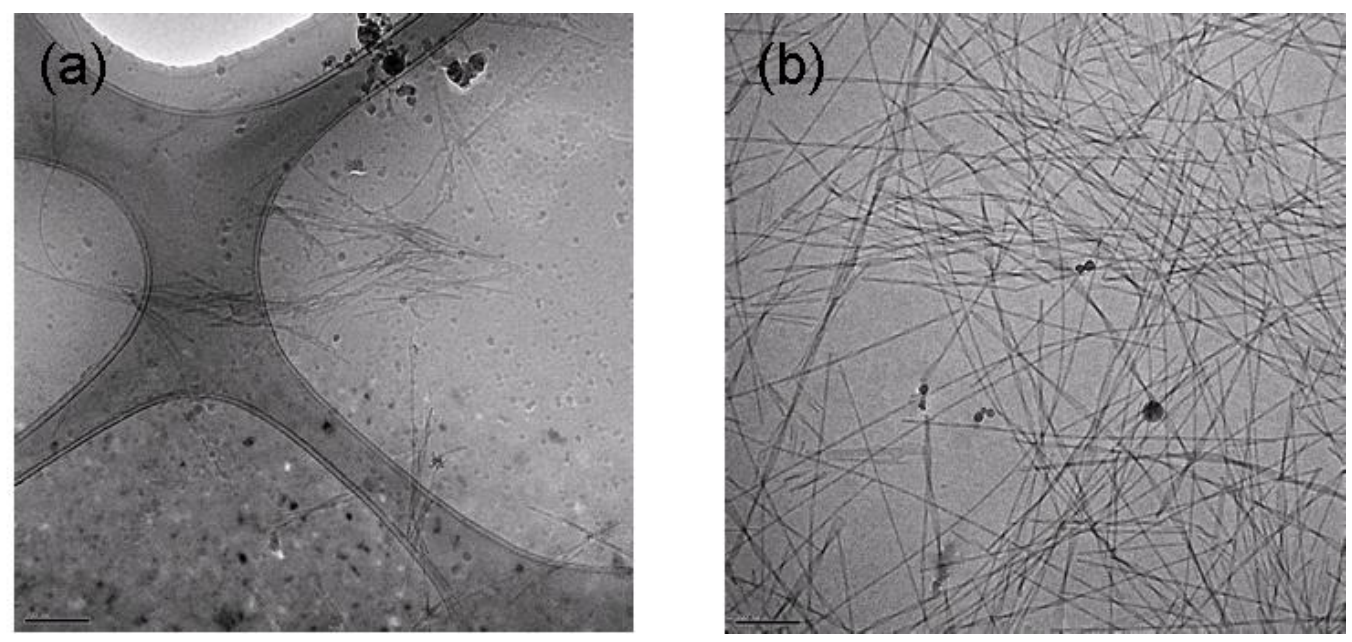

Fig.6. Cryo-TEM images. (a) Fmoc-RGDS (2\% wt in water), (b) Fmoc-GRDS (1\% wt in water). The scalebars represent $200 \mathrm{~nm}$. 


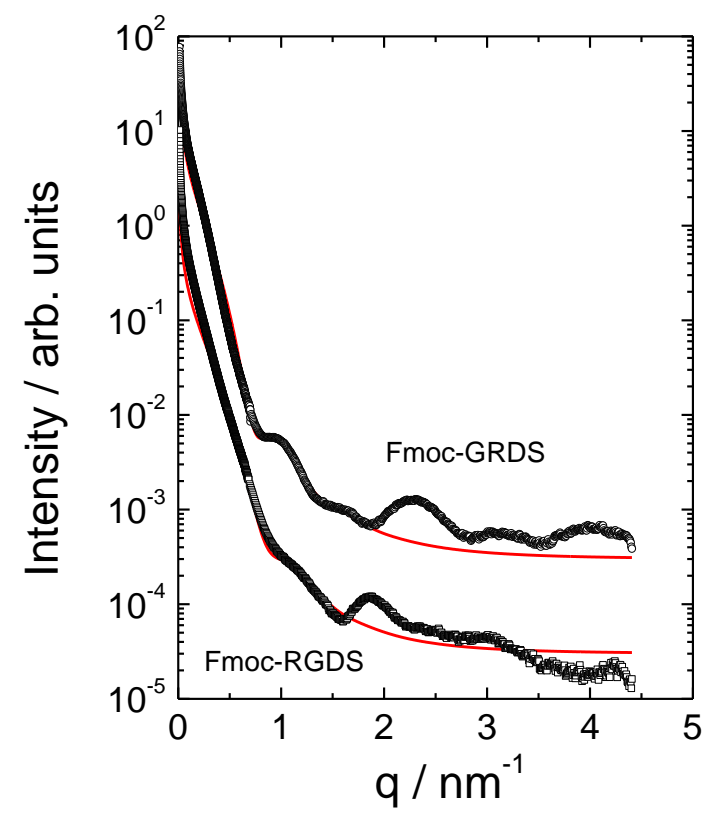

Fig.7. SAXS data $\left(30^{\circ} \mathrm{C}\right)$ for $2 \mathrm{wt} \%$ solutions including (red line) cylinder form factor fits. The data for Fmoc-RGDS has shifted (intensity reduction by a factor of 10) for convenience. 


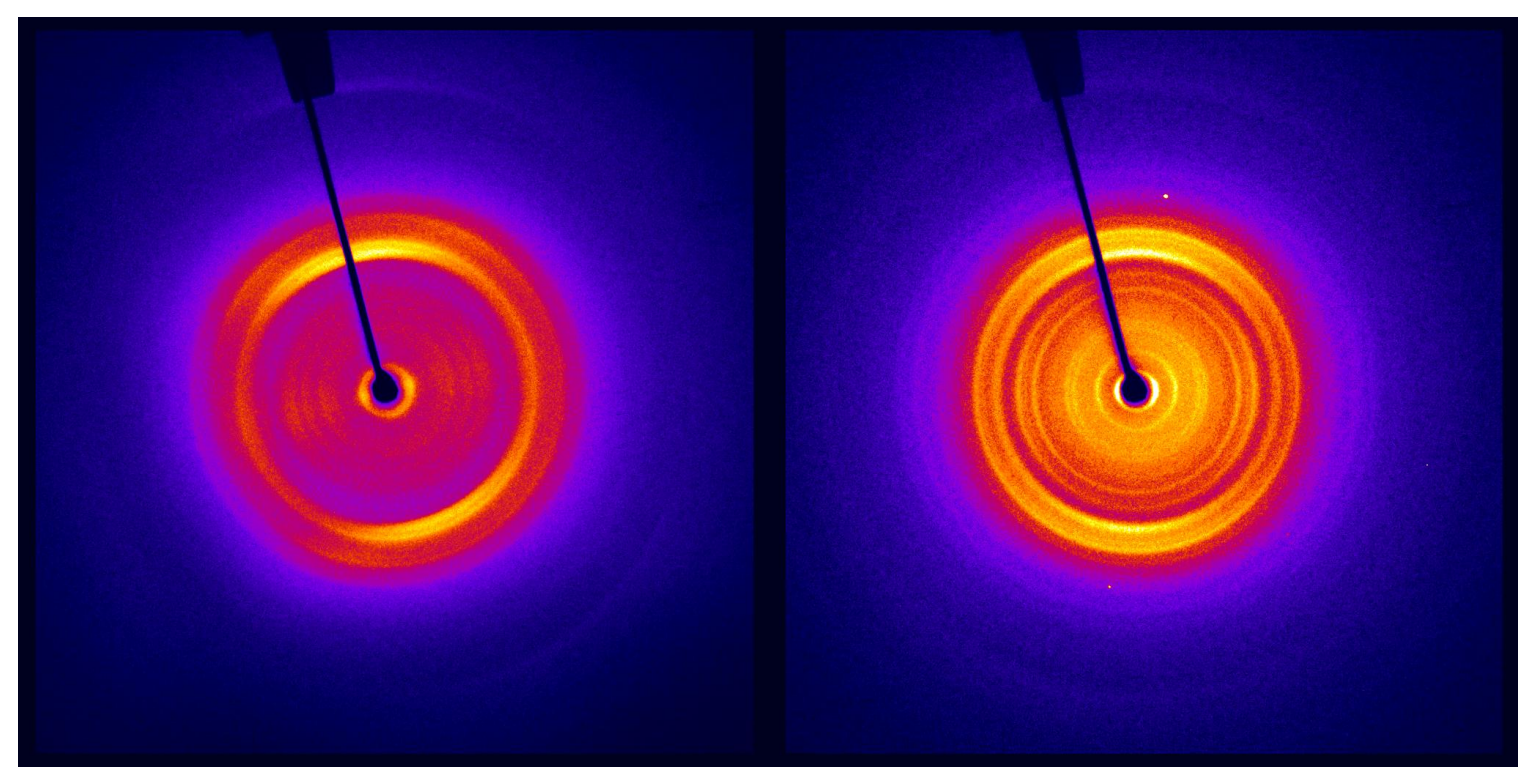

(a)

(b)

Fig.8. Fibre x-ray diffraction patterns obtained from dried stalks. (a) Fmoc-RGDS, (b) Fmoc-GRDS. 


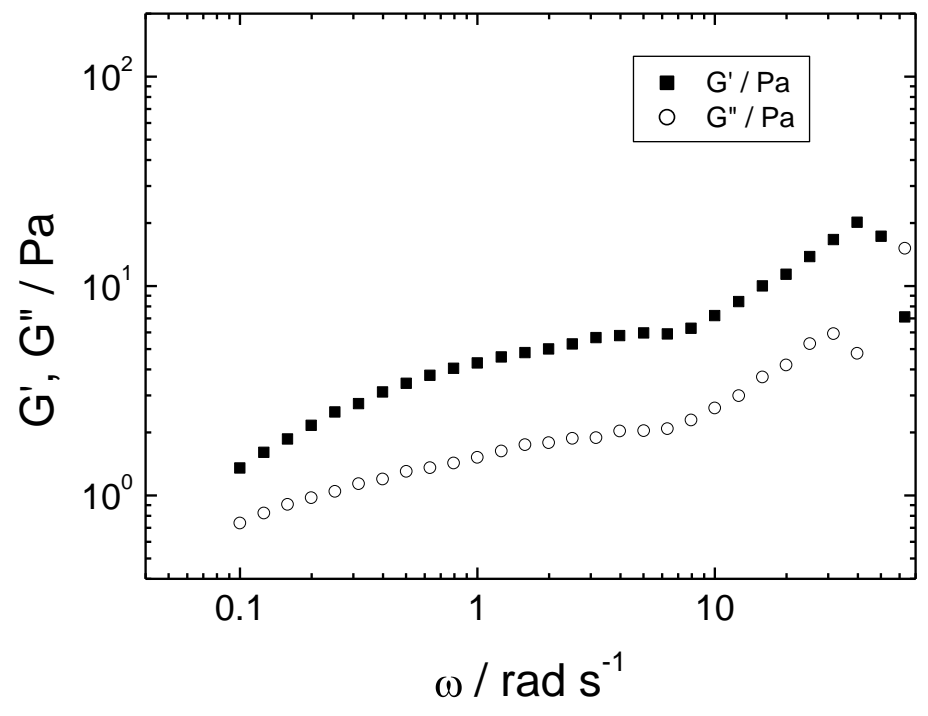

Fig.9. Frequency sweep of dynamic moduli for a $2 \mathrm{wt} \%$ gel of Fmoc-GRDS (controlled stress $\sigma=0.2 \mathrm{~Pa}$ ). 
(a)
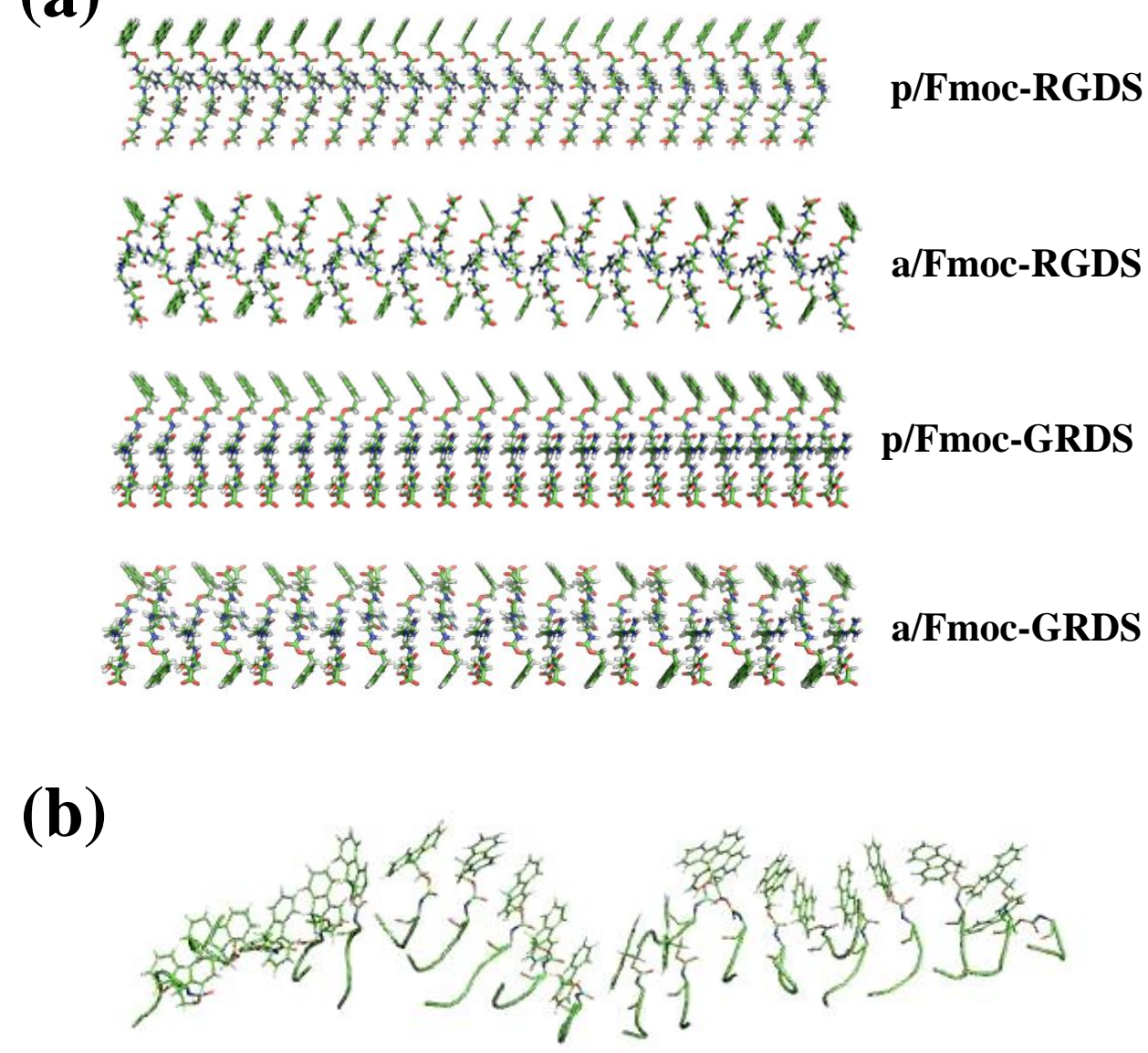

Fig. 10. (a) Starting structures of the four systems investigated considering 21 peptide molecules. (b) Last snapshot recorded from the $10 \mathrm{~ns}$ MD simulations of the p/FmocRGDS peptide. For clarification, only the backbones (cylinders) and the Fmoc group (explicit atomic description) have been included in the image. 
(a)

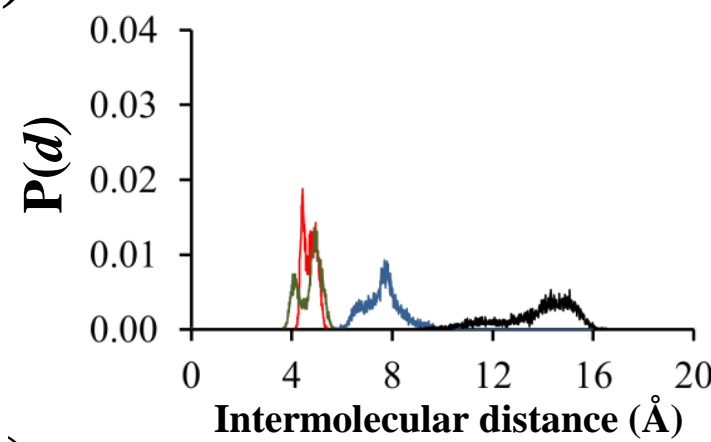

(b)

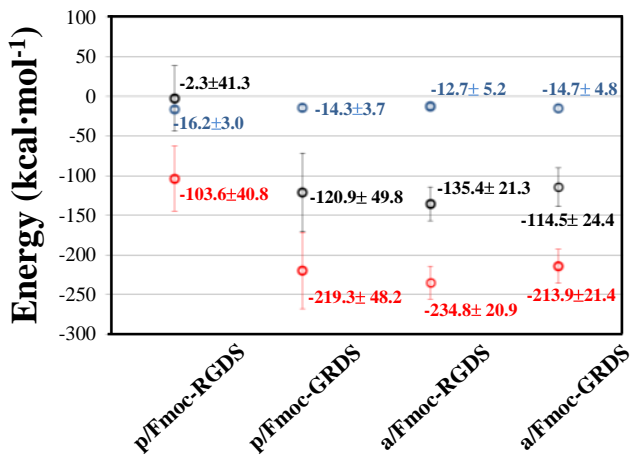

21 molecules

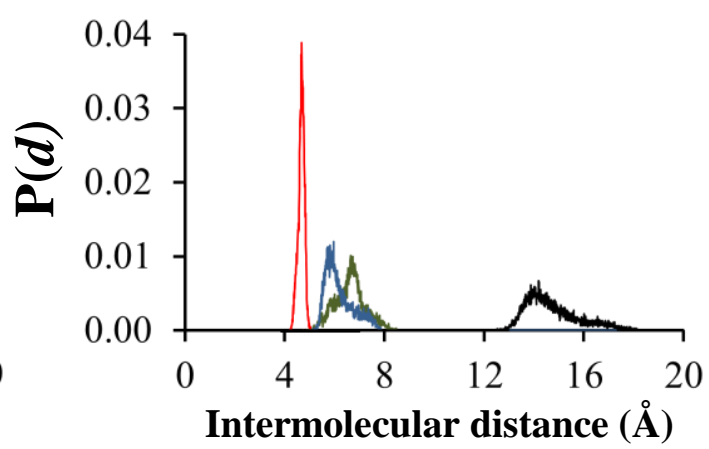

Fig. 11. (a) Probability distribution functions for the average intermolecular distances for the systems with 7 (left) and 21 (right) peptide molecules. Color code: red for p/Fmoc-RGDS, green for $\mathrm{p} /$ Fmoc-GRDS, blue for a/Fmoc-RGDS and black for a/Fmoc-GRDS. (b) Comparison of the average relative total internal energy (black), electrostatic energy (red) and van der Waals energy (blue) for systems with 7 (left) and 21 (right) peptide molecules. Energies have been calculated per molecule of peptide. Standard deviations are included in all cases. 
TOC Entry 